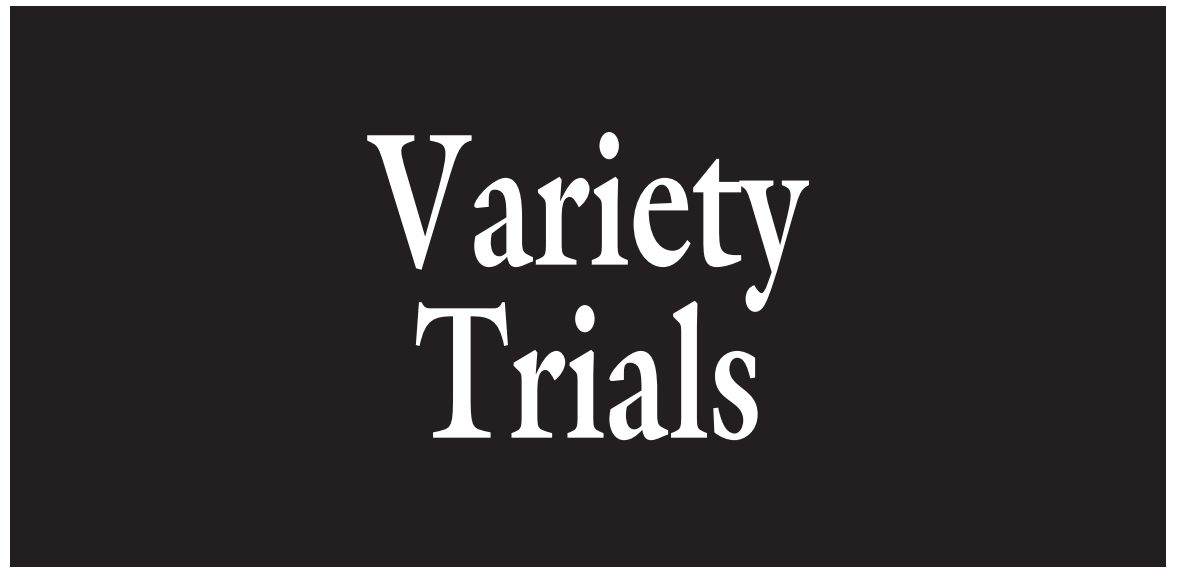

\section{Bloom and Harvest Dates, Fruit Quality Attributes, and Yield of Modern Peach Cultivars in the Intermountain Western United States}

\author{
Esmaeil Fallahi ${ }^{1,4,8}$, Bahar Fallahi ${ }^{1,5}$, Bahman Shafii ${ }^{2,6}$, \\ and Mohammad E. Amiri ${ }^{3,7}$
}

ADDITIONAL INDEX wORDs. adaptability, growing degree-days, Prunus persica, variety evaluation

$\overline{\text { Summary. Production of peaches (Prunus persica) in southwestern Idaho and other }}$ states in the intermountain western United States has increased during recent years, requiring information on the performance of modern cultivars in the region. Thus, a long-term project was conducted to investigate bloom date, harvest date, cumulative growing degree-days, fruit quality, and yield of various yellow- and white-fleshed peaches under conditions of southwestern Idaho during 2003 to 2007. The analysis of average response over these years indicated that 'Snow Giant', 'Jupiter', 'Yuko King', 'Burpeach Six', 'Fairtime', 'Coral Star', 'July Sun', and 'Zee Lady' bloomed earlier (5-7 Apr.), while 'Sierra Gem', 'Fancy Lady', and 'Red Star' bloomed later (11-12 Apr.) than other cultivars. 'Crimson Lady', 'May Sun', and 'Sierra Gem' were the earliest cultivars, had smaller fruit, and on average were harvested on 11, 13, and 24 July and needed 94, 96, and 103 days from full bloom to harvest, respectively. 'Opal Moncav', 'August Flame', 'August Lady', 'Ryan Sun', 'September Snow', 'Yukon King', and 'Fairtime' were harvested during the second half of September. The periods between bloom and harvest for these cultivars on average were 160, 163, 163, 168, 171, 173, and 177 days, respectively, and these cultivars often had greater soluble solids concentrations than other cultivars.

'PF12B' and 'PF15A' were "mid-season," but 'PF 20-007' and 'PF 24-007' were "late-season” cultivars. 'PF12B', 'PF15A', 'PF 20-007', 'Star Fire', 'Burapeach Six', 'Coral Star', 'All Star', and 'Zee Lady' had higher yield than many of the other cultivars. While the "early-season" cultivars can be planted for regional and local market, the "mid-season" and "late-season" peaches are excellent choices for marketing during September and early October when production of the similar cultivars are already completed in warmer regions. Overall, 'Sweet Dream', 'August Lady', 'Zee Lady', 'August Flame', 'Snow Giant', 'Saturn', 'Jupiter', and 'PF24007 ' showed satisfactory to great performance in this long-term evaluation.

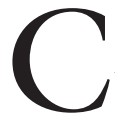
ommercial peach production in Idaho is dated back to 1870 . Cultivars Early Red Haven, Late Redhaven, Redglobe, Early Hale, J.H. Hale, and Improved Elberta are among the popular cultivars of peaches that are still in production after many decades of their initial planting in
Census, 2007). Similar to the situation in other peach-producing states (Frecon et al., 2002), the best orchard sites are taken for development and urbanization in Idaho. However, new peach orchards are often planted in old apple (Malus $\times$ domestica cv. Delicious) orchard sites. This increase is due to the national and international market demands for high-quality peaches produced under high desert conditions of intermountain western United States, including southwestern Idaho and central Washington. Warm and dry days and cool nights during the growing season create suitable conditions for growing high-quality peaches and nectarines in this region. The pressure for urbanization and the competitive nature of the world market mandate production of new cultivars with high quality that mature over several weeks for a wide market window. The California Tree Fruit Agreement (CTFA, 2003) and Huang et al. (2008) classified peaches into five categories, according to their period between full bloom and harvest: 1) "very early cultivars," which have less than $65 \mathrm{~d}$ from full bloom to harvest, 2) "early cultivars," which have 66 to $90 \mathrm{~d}$ from full bloom to harvest, 3 ) "midseason cultivars," which have 91 to 120 d from full bloom to harvest, 4) "lateseason cultivars," which have 121 to $150 \mathrm{~d}$ from full bloom to harvest, and 5 ) "very late cultivars," which have more than $151 \mathrm{~d}$ from full bloom to harvest. Cultivars in each group have their advantages and disadvantages, and they are planted according to the marketing outlet and strategy of each grower. Okie et al. (2008) have described the history, quality attributes, marketing status, and breeding strategies of various peach cultivars in different regions to fulfill the needs of today's peach market. According to that report, most breeding for fresh market peaches follows similar protocols. Advanced selections and cultivars from in-house as well as other breeding programs are evaluated to find superior parents. Parents with superior characteristics are crossed by hand to produce seedlings that combine the desirable qualities of the parents.

Consumer preference for whitefleshed nectarines and peaches may vary according to individual consumer preference and ethnic background, while yellow-fleshed peaches and nectarines are generally accepted by most 
consumers. In general, white-fleshed peaches and nectarines are popular among consumers of Asian ethnic backgrounds, but these cultivars are not well known by other American consumers (Bruhn et al., 1991). Many white-fleshed peaches are highly susceptible to bruising and have a low acid content (Brooks and Olmo, 1972 and 1997; Crisosto et al., 2001; Okie, 1998; Whealy and Demuth, 1993). Crisosto et al. (2001) reported that a large variability in titratable acidity (TA), soluble solids concentrations (SSC), bruising and flesh browning susceptibility, and market life was found for several white-fleshed peach and nectarine cultivars under conditions in the San Joaquin Valley of California. During ripening off the tree, SSC did not increase nor did TA decrease; thus, the SSC/TA remained the same in these stone fruit (Crisosto et al., 2001). Because of these characteristics, it was suggested that white-fleshed peaches and nectarines can be eaten when still firm if hard texture is not a concern. Frecon et al. (2002) compared the peach and nectarines developed in New Jersey with some white-fleshed cultivars from other locations and found that 'Carolina Belle', 'Klondlike', 'Blushing Star', 'Sugar Giant', 'Snow Giant', and 'Arctic Jay' showed promise for planting on the basis of fruit quality.

In spite of the increasing commercial importance of and the increasing trend in peach production, there is no comprehensive information on the bloom and harvest dates, yield, or quality of these fruit in the southwestern Idaho of the intermountain western region of the United States. The goal of this longterm project was to investigate bloom date, maturity and harvest date, yield, and fruit quality of various yellowand white-fleshed peaches under conditions of southwestern Idaho.

\footnotetext{
${ }^{1}$ Department of Plant, Soil, and Entomological Sciences, Parma Research and Extension Center, University of Idaho, Parma, ID 83660

${ }^{2}$ Statistical Programs, College of Agricultural and Life Sciences, University of Idaho, Moscow, ID 83844

${ }^{3}$ Department of Horticulture, University of Zanjan, Zanjan, Iran.

${ }^{4}$ Professor and Director of Pomology.

${ }^{5}$ Research Associate of Pomology.

${ }^{6}$ Professor and Director of Statistical Programs.

${ }^{7}$ Associate Professor of Horticulture.

${ }^{8}$ Corresponding author. E-mail: efallahi@uidaho.edu.
}

\section{Materials and methods}

The experimental orchard was located at the University of Idaho Parma Research and Extension Center near Parma, ID. This orchard was located in southwestern Idaho, which was a representative area of fruit-producing orchards in the intermountain western United States region (lat. $43^{\circ} 48^{\prime} 00^{\prime \prime} \mathrm{N}$, long. $\left.116^{\circ} 56^{\prime} 00^{\prime \prime} \mathrm{W}\right)$ with an annual precipitation of about 10.8 inches, an average minimum daily temperature of $-17.6^{\circ} \mathrm{F}$ in January and an average maximum daily temperature of $93.2^{\circ} \mathrm{F}$ in July, and an elevation of $2305 \mathrm{ft}$.

Uniform peach trees on 'Nemaguard' rootstock, with an average of 0.5 -inch diameter, were obtained from various nurseries in California and Washington. Thirty-eight peach cultivars or selections were planted at $8 \times 16.5$-ft spacing in Apr. 2000. The list of cultivars is presented in Tables 1 through 4. 'Burapeach Six', 'August Flame', and 'Summer Flame' were named B4.098, B2.034 ('Burapeach Four'), and C12.001, respectively, when they were at experimental stages.

Trees were trained into a fourleader vase-shaped system. Trees were also pruned during the summer to facilitate light penetration through the canopy.

The soil was sandy loam and at the depth of 0 to 24 inches, and the soil characteristics were as follows: $\mathrm{pH} 7.1$ to 7.3 , nitrate nitrogen $\left(\mathrm{NO}_{3}-\mathrm{N}\right) 2.74$ to $3.14 \mu \mathrm{g} \cdot \mathrm{g}^{-1}$, ammonium nitrogen $\left(\mathrm{NH}_{4}-\mathrm{N}\right) 1.45$ to $1.09 \mu \mathrm{g} \cdot \mathrm{g}^{-1}$, phosphorous (P) 8.0 to $12.4 \mu \mathrm{g} \cdot \mathrm{g}^{-1}$, potassium $(\mathrm{K}) 306$ to $319 \mu \mathrm{g} \cdot \mathrm{g}^{-1}$, cation exchange capacity (CEC) 0.166 to $0.183 \mathrm{meq} / \mathrm{g}$, and organic matter $0.48 \%$ to $1.03 \%$.

Urea nitrogen $\left[\mathrm{CO}\left(\mathrm{NH}_{2}\right)_{2}\right]$ mixed with potassium chloride $(\mathrm{KCl})$ and $\mathrm{P}$ were applied during the month of May annually to provide $\mathrm{N}, \mathrm{P}$, and $\mathrm{K}$ at rates of 110,50 , and 60 $\mathrm{lb} / \mathrm{acre}$, respectively. This mixed fertilizer was broadcasted in an $\approx 3-\mathrm{ft}$ band on either side of tree rows. Trees were irrigated weekly with under-tree sprinklers to match the evapotranspiration requirement for peach crop $(E T c)$. We used information from the Agrimet Weather Station at the University of Idaho, Parma, ID, to calculate ETc. Annual pruning, spray, and other cultural practices in this experiment were similar to those of commercial orchards in the region.

Dates of full bloom (about $80 \%$ blooms open) and commercial harvest (when most of the fruit were ready to be harvested) for each tree were recorded every year in 2003 to 2007. In addition to the actual dates, the number of "days from 1 Jan. (DJ)" to full bloom was also computed. Daily growing degreedays (DGDD) from l Jan. to full bloom and harvest dates were calculated as: [(daily maximum plus minimum temperatures $\left.\left.{ }^{\circ} \mathrm{F}\right) / 2-\left(40^{\circ} \mathrm{F}\right)\right]$. Cumulative degree-days (GDD) were calculated as the sum DGDD to the full bloom or harvest dates for each cultivar in each year. We chose to use $40{ }^{\circ} \mathrm{F}$ as the base temperature in the DGDD calculations because even at this temperature, bloom will develop although the rate of development is slower (E. Fallahi, personal observation and unpublished data).

Fruit color was described visually and total yield per tree was measured at harvest time every year in 2003 to 2006. At commercial harvest time, 10 fruit were randomly sampled from each tree and average fruit weight was measured in 2003 to 2005 and SSC was measured in 2004 and 2005 with a hand-held temperature-compensated refractometer (Nl; Atago, Tokyo). Fruit skin and flesh color were inspected visually and described. Fruit of each cultivar was evaluated by several people at harvest and the flavor was described objectively.

\begin{tabular}{llll}
\hline $\begin{array}{l}\text { Units } \\
\text { To convert U.S. to SI, } \\
\text { multiply by }\end{array}$ & U.S. unit & SI unit & $\begin{array}{l}\text { To convert SI to U.S., } \\
\text { multiply by }\end{array}$ \\
\hline 0.3048 & $\mathrm{ft}$ & $\mathrm{m}$ & 3.2808 \\
25.4 & $\mathrm{inch}(\mathrm{es})$ & $\mathrm{mm}$ & 0.0394 \\
0.4536 & $\mathrm{lb}$ & $\mathrm{kg}$ & 2.2046 \\
1.1209 & $\mathrm{lb} / \mathrm{acre}$ & $\mathrm{kg} \cdot \mathrm{ha}^{-1}$ & 0.8922 \\
1 & $\mathrm{meq} / \mathrm{g}$ & $\mathrm{mol} \cdot \mathrm{kg}^{-1}$ & 1 \\
28.3495 & $\mathrm{oz}$ & $\mathrm{g}$ & 0.0353 \\
1 & $\mathrm{ppm}$ & $\mu \mathrm{\mu g} \cdot \mathrm{g}^{-1}$ & 1 \\
$\left({ }^{\circ} \mathrm{F}-32\right) \div 1.8$ & ${ }^{\circ} \mathrm{F}$ & ${ }^{\circ} \mathrm{C}$ & $\left(1.8 \times{ }^{\circ} \mathrm{C}\right)+32$
\end{tabular}


Experimental Design. The experimental orchard was arranged as a completely randomized design with six replications per cultivar. Data were analyzed using general linear model (GLM) procedures. Fisher's protected LSD $(\alpha=0.05)$ was used to separate treatment means. Statistical analyses were carried out using SAS (version 9.2; SAS Institute, Cary, NC).

\section{Results and discussion}

BLOOM DATES AND GDD FOR вLоом. In Table 1 , peach cultivars are listed according to their longterm average full bloom dates and the number of days from 1 Jan. to full bloom (DJ). Considering all cultivars over the period of 2003 to 2007 , dates of full bloom ranged from 30 March to 25 Apr. (a total of $26 \mathrm{~d}$ ). Averaging values for actual full bloom dates or days from 1 Jan. from 2003 to 2007 revealed a 7 -d or $89^{\circ} \mathrm{F}$ GDD difference between the earliestblooming and latest-blooming cultivars. These average values showed that 'Snow Giant', 'Jupiter', 'Yuko
King', 'Burpeach Six', 'Fairtime', 'Coral Star', 'July Sun', and 'Zee Lady' bloomed earlier (5-7 Apr.), while 'Sierra Gem', 'Fancy Lady', and 'Red Star' bloomed later (11-12 Apr.) than other cultivars (Table 1). In this experiment, the variation for full bloom time was greater between years than among cultivars within a given year. Trees within each cultivar and each year had very small variation in their full-bloom dates due to the tree and soil uniformity (data not shown). There was no significant

Table 1. Full bloom date (FB), cumulative growing degree-days (GDD), and number of days from 1 Jan. to full bloom (DJ) for various cultivars of peaches grown under southwestern Idaho conditions.

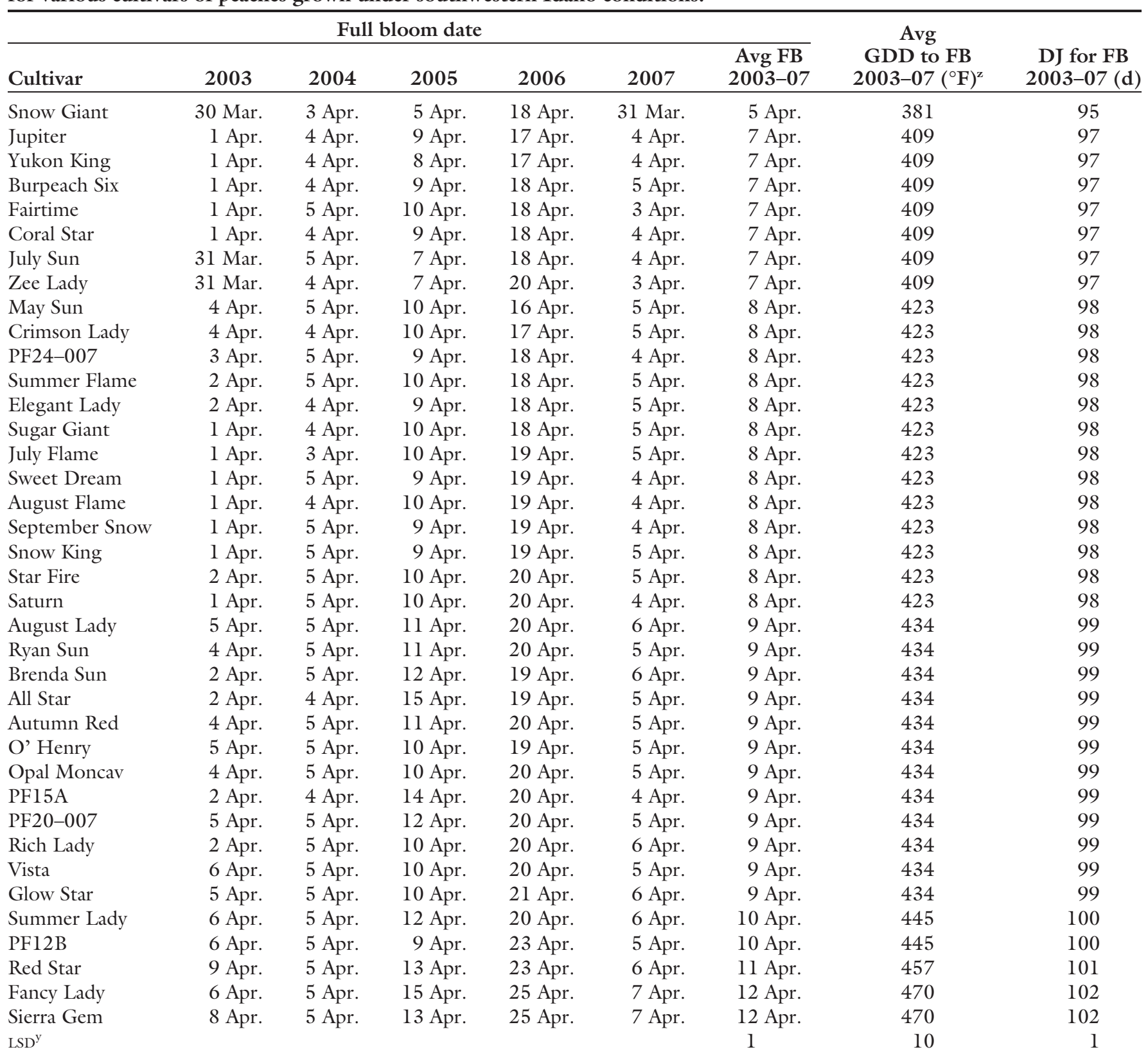

${ }^{2}\left({ }^{\circ} \mathrm{F}-32\right) \div 1.8={ }^{\circ} \mathrm{C}$.

yean separation within columns, using least significant difference (LSD) at $P \leq 0.05$. 
interaction between years and cultivars for any of the bloom date measurements. It is difficult to pre-plan for some cultural practices such as blossom thinning in the cultivars that exhibit wide tree-to-tree or year-toyear variations in bloom, based on historical data.

During warmer seasons, differences still existed between cultivars but the differences were less than those in cooler seasons. For example, GDD for the period between 30 Mar. and 25 Apr. was $291.2{ }^{\circ} \mathrm{F}$ in 2005 and $399.2^{\circ} \mathrm{F}$ in 2004 (data not shown). However, the difference between the earliest- and the latest-blooming cultivars was $10 \mathrm{~d}$ in 2005 and $2 \mathrm{~d}$ in 2004 (Table 1). Historically, starting 1 May, the chance of spring frost diminishes significantly in southwestern Idaho. Therefore, the late-blooming cultivars such as 'Fancy Lady', 'Red Star', and 'Sierra Gem' may have a lower risk of frost damage.

Commercial harvest Date. Cultivars in Tables 2 through 4 are arranged in ascending order of their 2003 to 2007 average harvest dates. Significant differences existed in commercial harvest dates among cultivars (Table 2). Harvest date for each cultivar varied from year to year, but the order of harvest among cultivars mostly stayed the same in each season, and no significant interaction existed between cultivars and years. The differences among cultivars were greater for harvest dates than for bloom dates. For example, the difference between the earliest and latest cultivars for full bloom dates was only $7 \mathrm{~d}$, while for harvest dates, it was $83 \mathrm{~d}$ (the difference between 11 July and 1 Oct.). The earliest cultivar in our evaluation was 'Crimson Lady', which needed $94 \mathrm{~d}$ between full bloom, and on average, was harvested on 11 July. Thus, the earliest cultivar in our evaluation fits in the "midseason" category of Huang et al. (2008). 'May Sun' and 'Sierra Gem' were also early, and, on average, harvested on 13 July and 24 July and needed 96 and $103 \mathrm{~d}$ from full bloom to harvest, respectively (Table 2). 'Opal Moncav', 'August Flame', 'August Lady', 'Ryan Sun', 'September Snow', 'Yukon King', and 'Fairtime' were harvested during the second half of September, and the periods between bloom and harvest for these cultivars were 160, 163, 163,
$168,171,173$, and $177 \mathrm{~d}$, respectively. Thus, these peaches are considered "very late" cultivars according to the CTFA (2003) and Huang et al. (2008) categorization.

PF series cultivars had different harvest dates. 'PF12B' and 'PF15A' were "mid-season" cultivars and were harvested on 8 Aug. (120 and $121 \mathrm{~d}$ from full bloom), respectively. However, 'PF 20-007' and 'PF 24007' were "late-season" cultivars and were harvested on 17 Aug. (130 d from full bloom) and 24 Aug. (138 d from full bloom), respectively.

In the highly competitive peach market, in addition to climatic conditions, time of harvest (early, mid, or late season), quality attributes, and yield should be considered before planting a cultivar. According to the CTFA (2003), of the total number peach trees sold in California during 1999 to 2002 , $43.1 \%$ were in a combination of "very early season" and "early-season" categories, while $39 \%$ and $17.9 \%$ were in "mid-season" and "late-season" categories, respectively. A comparison of results of selected cultivars used in the CTFA report (2003) and our experiment revealed that peaches matured several weeks later in southwestern Idaho than in California. It is noteworthy that the maturity differences between California and Idaho were greater for early-maturing cultivars than late-maturing ones (Table 2). For example, these differences were 46,52 , and $49 \mathrm{~d}$ for the earliermaturing cultivars of 'Crimson Lady', 'Rich Lady', and 'Vista', respectively, while they were, 34, 28, and $26 \mathrm{~d}$ for the late-maturing cultivars of 'Ryan Sun', 'September Snow', and 'Fairtime', respectively. In New Jersey, 'Saturn', 'Sugar Giant', and 'Snow King' were harvested on 21 July, 12 Aug., and 20 Aug., respectively (Frecon et al., 2002). However, in Idaho, these three cultivars were harvested between 2 to 3 weeks later (Table 2). Comparison of these harvest dates underscores the importance of producing peaches with different harvest times in southwestern Idaho. Our "early-season" peaches mature at a time that many "mid-season" peaches from California are in the market. Thus, our early cultivars would be more appropriate for local and farmers' markets. However, "medium-" and "late-season" peaches (Table 2) are harvested at the time that
California marketing for those cultivars has slowed down or finished, and thus provide an excellent market window for growers in southwestern Idaho and other similar regions in the intermountain western region of the United States. Results in Tables 2 to 4 provide options to peach growers to select cultivars with different flesh color and flavor best suited to their operations. However, because many peach growers in Idaho and the intermountain western region of the United States also grow apples, the harvest time of late peaches may overlap with the apple harvest, and this should be considered before planting.

\section{Fruit quality attributes and yield}

Fruit COLOR. Descriptions for fruit skin and flesh color are presented in Table 3, and other quality attributes and yield are shown in Table 4. Fruit color can be affected by extent of light penetration through the tree canopy, but all cultivars were trained, pruned, and thinned similarly, and thus, descriptions in Table 3 reflect their relative colors. Although fruit flesh colors are generally categorized as yellow or white, a range of skin color such as red, blushed, and yellow was observed in these cultivars. 'Sweet Dream', 'Zee Lady', 'PF24007', 'Jupiter', 'August Flame', 'Yukon King', 'Sugar Giant', 'September Snow', 'Opal Moncav', and 'Jupiter' had distinctively attractive skin and flesh color. For example, 'Sweet Dream' had red to dark maroon color. 'Yukon King' had an extremely attractive creamy white with pink to dark red skin color. 'Fairtime' had distinctively yellow skin and bright yellow flesh.

Fruit SIZE (WEIGHT). Earlyripening cultivars such as 'Crimson Lady', 'May Sun', 'Sierra Gem', 'Saturn', and 'Vista' had smaller fruit and their long-term average fruit weights were less than $200 \mathrm{~g}$ (Table 4). 'Yukon King', 'PF24-007', 'Coral Star', 'Sugar Giant', 'August Flame', 'Snow Giant', 'Fairtime', and 'August Lady' had consistently larger fruit than many other cultivars, and their average fruit weights exceeded $260 \mathrm{~g}$ over 2003 to 2005 (Table 4). 'PF24007' had numerically the largest average fruit weight among all cultivars $(280.3 \mathrm{~g})$, but the fruit weight of this cultivar was not significantly 


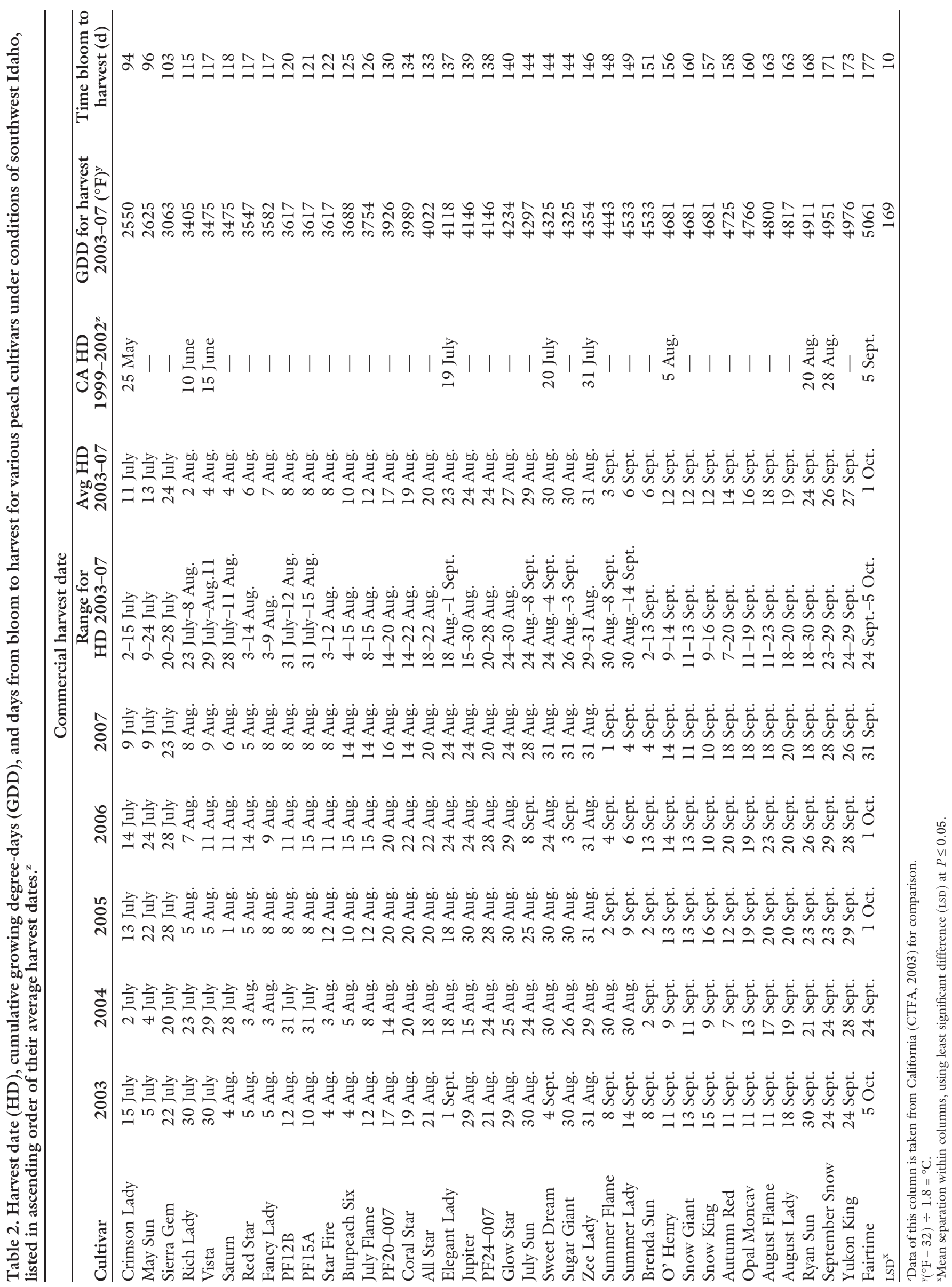


Table 3. Description of skin and flesh color of different peach cultivars under conditions of southwest Idaho, listed in ascending order of their harvest dates.

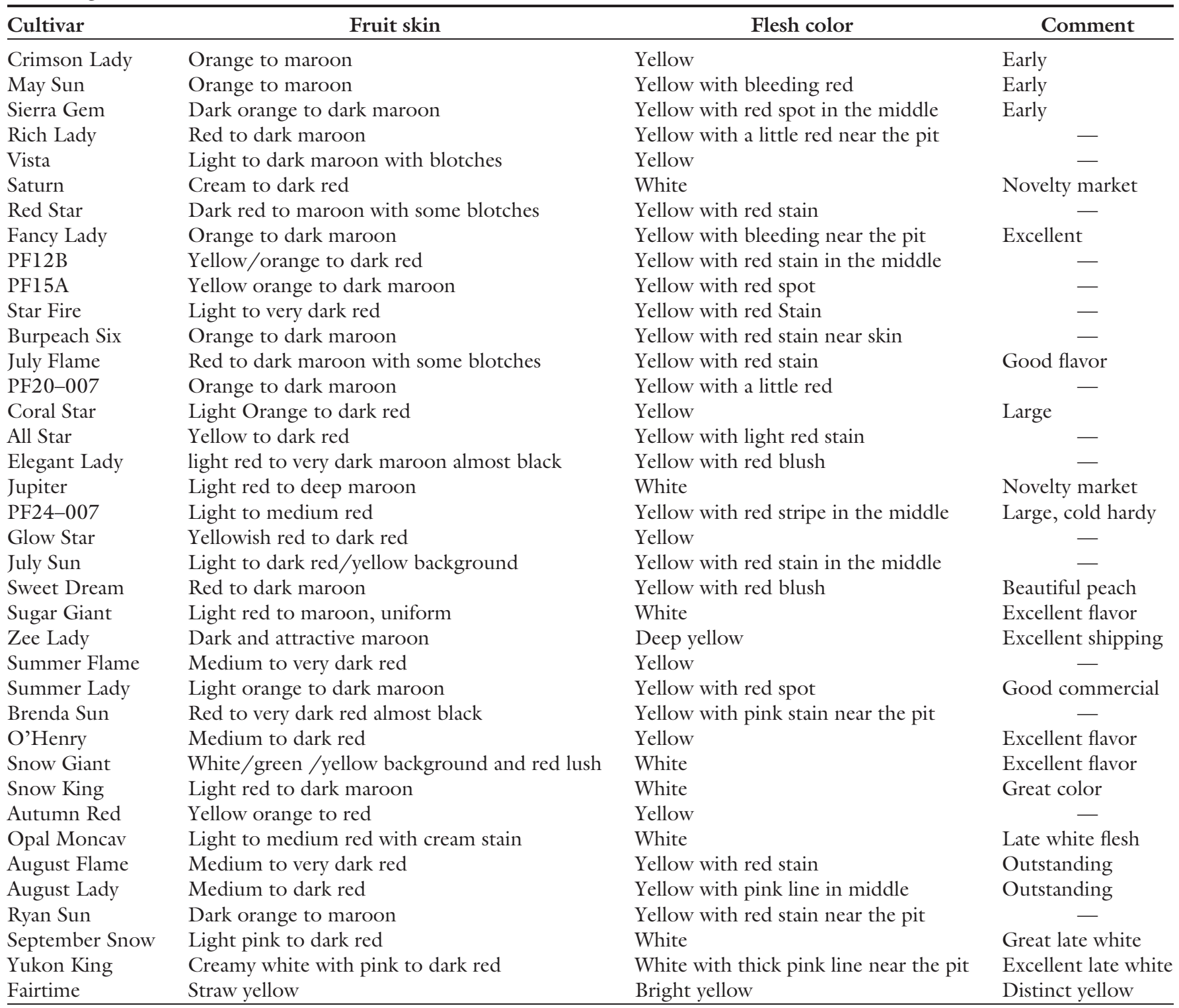

different from that of 'Coral Star'. It is noteworthy that these cultivars represent "mid-season" and "late-season" peaches according to the CTFA (2003). The larger fruit size in some of these cultivars was inversely correlated to their lighter yield.

SSC. Generally, SSC increased with ripening season (Table 4 ). With the exception of 'Ryan Sun' and 'Fairtime', fruit of the late-ripening cultivars that on average were harvested after 14 Sept. (Table 2) had greater than $13 \%$ SSC (Table 4). "Flat" peaches had high SSC values. 'Jupiter' had significantly higher SSC (overall average of $15.0 \%$ ) than all other cultivars. 'Saturn' (another flat peach) had higher SSC values than all other cultivars except 'Jupiter' and 'Yukon King'. Frecon et al. (2002) also reported that 'Saturn' was among cultivars with high SSC in New Jersey. Among all cultivars, 'PF15A', 'Coral Star', and 'All Star' consistently had less than $10 \%$ SSC in 2 years (Table 4 ). The taste survey showed that 'All Star' and 'Coral Star' had relatively "flat" taste (data not shown) that could have been as a result of their low SSC. These cultivars had larger fruit weight (Table 4) and perhaps higher fruit water content than many other cultivars, leading to a lower SSC value due to a dilution effect. However, 'PF24-007' peach had large size and low SSC but had good flavor. Also, cultivars such as 'August Flame' and 'August Lady' had greater than $13 \%$ SSC in spite of their large fruit size. Most of the white-fleshed peaches had higher SSC values than yellow-fleshed peaches, which is in agreement with results reported by Robertson et al. (1990).

YIELD. All cultivars had lower yields in 2003 compared with other years because the trees were young. 'Crimson Lady', which was the earliest cultivar to harvest, had the lowest yield, perhaps due to its small fruit size (Table 4). However, 'Sierra Gem' (also an early-maturing cultivar) was among the high-yielding cultivars every year. 'PFl2B', 'PF15A', 'Star Fire', 'Burpeach Six', 'PF20-007', 'Coral Star', and 'All Star' 
Table 4. Peach cultivar quality attributes (fruit size and soluble solids concentration) and yield under the conditions of southwest Idaho, listed in ascending order of their average harvest dates. ${ }^{\mathrm{z}}$

\begin{tabular}{|c|c|c|c|c|c|c|c|c|c|c|c|c|}
\hline \multirow[b]{2}{*}{ Cultivar } & \multicolumn{4}{|c|}{$\operatorname{Avg}$ fruit wt $(g)^{y}$} & \multicolumn{3}{|c|}{ Soluble solids concn $(\%)$} & \multicolumn{5}{|c|}{ Yield/tree $(\mathrm{kg})^{\mathrm{y}}$} \\
\hline & 2003 & 2004 & 2005 & $\frac{\text { Avg }}{2003-05}$ & 2004 & 2005 & $\frac{\text { Avg }}{2004-05}$ & 2003 & 2004 & 2005 & 2006 & $\begin{array}{c}\text { Avg } \\
2003-06 \\
\end{array}$ \\
\hline Crimson Lady & & 143.3 & 182.4 & 162.9 & 10.7 & 11.3 & 11.0 & 3.6 & 11.5 & 7.6 & 11.0 & 8.4 \\
\hline May Sun & 106.7 & 155.4 & 172.5 & 144.9 & 11.8 & 11.7 & 11.8 & 6.4 & 18.4 & 12.0 & 14.0 & 12.7 \\
\hline Sierra Gem & 167.1 & 198.6 & 207.5 & 191.1 & 11.1 & 10.5 & 10.8 & 15.0 & 23.4 & 22.6 & 29.8 & 22.7 \\
\hline Rich Lady & 166.9 & 169.8 & 224.5 & 187.1 & 11.1 & 12.1 & 11.6 & 9.2 & 16.4 & 10.4 & 12.6 & 12.16 \\
\hline Red Star & 190.8 & 191 & 196 & 192.6 & 12.6 & 12.3 & 12.5 & 17.0 & 17.4 & 10.2 & 29.9 & 18.6 \\
\hline Fancy Lady & 179.7 & 206.7 & 220.5 & 202.3 & 11.8 & 11.3 & 11.6 & 14.6 & 18.4 & 13.0 & 27.6 & 18.4 \\
\hline PF12B & 185.3 & 198.9 & 241.9 & 208.7 & 11.8 & 12.5 & 12.2 & 13.1 & 25.4 & 23.8 & 33.28 & 23.9 \\
\hline PF15A & 150.5 & 224.2 & 241 & 205.2 & 9.8 & 9.7 & 9.8 & 24.6 & 36.1 & 13.4 & 30.1 & 26.0 \\
\hline Star Fire & 203.1 & 225.5 & 252.7 & 227.1 & 10.7 & 11.6 & 11.2 & 18.0 & 25.9 & 17.9 & 41.8 & 25.9 \\
\hline Burpeach Six & 191.1 & 231.6 & 269.1 & 230.6 & 9.8 & 10.4 & 10.1 & 23.3 & 31.9 & 18.0 & 38.9 & 28.0 \\
\hline All Star & 220.4 & 257.8 & 282.1 & 253.4 & 9.6 & 9.3 & 9.5 & 17.3 & 40.0 & 20.6 & 29.8 & 26.9 \\
\hline Elegant Lady & 212.5 & 219.9 & 219.4 & 217.3 & 11.2 & 11.5 & 11.4 & 6.0 & 14.9 & 14.1 & 20.6 & 13.9 \\
\hline Jupiter & & 122.2 & 126.7 & 124.5 & 14.2 & 15.7 & 15.0 & & 11.9 & 17.5 & 28.4 & 19.4 \\
\hline PF24-007 & 235.9 & 299.6 & 305.4 & 280.3 & 9.1 & 9.7 & 9.4 & 10.9 & 22.8 & 10.1 & 19.6 & 15.9 \\
\hline Glow Star & 212.0 & 246.7 & 274.8 & 244.5 & 11.3 & 10.9 & 11.1 & 13.6 & 12.5 & 21.1 & 21.7 & 17.2 \\
\hline July Sun & 237.2 & 227.3 & 265.3 & 243.3 & 12 & 12.1 & 12.1 & 4.0 & 14 & 10.5 & 18.7 & 11.8 \\
\hline Sweet Dream & 231.0 & 259.1 & 275.5 & 255.2 & 12.4 & 12.4 & 12.4 & 7.2 & 12.5 & 22.4 & 23.6 & 16.4 \\
\hline Sugar Giant & 267.6 & 291.6 & 258.6 & 272.6 & 11.3 & 10.2 & 10.8 & 5.7 & 16.4 & 15.1 & 18.4 & 13.9 \\
\hline Zee Lady & 190.2 & 180.1 & 189.1 & 186.5 & 10.8 & 11.2 & 11.0 & 15.0 & 40.0 & 17.4 & 23.0 & 23.9 \\
\hline Summer Flame & 231.3 & 249.2 & 258.7 & 246.4 & 10.5 & 11.8 & 11.2 & 1.3 & 12.9 & 7.6 & 17.8 & 9.9 \\
\hline Summer Lady & 229.5 & 230.5 & 261.9 & 240.6 & 11 & 13.4 & 12.2 & 10.9 & 13.4 & 5.8 & 15.7 & 11.5 \\
\hline Brenda Sun & 227.5 & 232.4 & 222.7 & 227.5 & 12.2 & 12.1 & 12.2 & 0.9 & 11.9 & 12.6 & 22.7 & 12.0 \\
\hline Ryan Sun & 180.9 & 298.0 & 286.5 & 255.1 & 12.4 & 11.5 & 12.0 & 9.9 & 14.9 & 14.6 & 17.6 & 14.2 \\
\hline September Snow & 190.9 & 247.3 & 224.2 & 220.8 & 13.4 & 13.0 & 13.2 & 9.1 & 16.4 & 14.6 & 16.7 & 14.2 \\
\hline Yukon King & 245.0 & 280.8 & 279 & 268.3 & 13.4 & 13.9 & 13.7 & 6.6 & 22.4 & 19.4 & 21.9 & 17.6 \\
\hline Fairtime & 243.9 & 267.0 & 274.1 & 261.7 & 12.0 & 12.2 & 12.1 & 12.0 & 14.7 & 18.1 & 23.1 & 17.0 \\
\hline LSD & 15.1 & 16.2 & 17.1 & 12.4 & 1.0 & 1.5 & 1.0 & 2 & 5.1 & 5.5 & 5.0 & 4.0 \\
\hline
\end{tabular}

${ }^{\mathrm{z}}$ Mean separation within columns by LSD at $P \leq 0.05$.

$\mathrm{y} 1 \mathrm{~g}=0.0353 \mathrm{oz} ; \mathrm{l} \mathrm{kg}=2.2046 \mathrm{lb}$.

consistently had higher yield than most other cultivars. Fruit size is often negatively associated with fruit number (E. Fallahi, personal observation and unpublished data). However, among these high-yielding cultivars, 'Coral Star' and 'All Star' also had larger fruit size despite their high yields, which makes them suitable as commercial cultivars, although the flavors of these cultivars were not distinctively superior to those of other cultivars.

Overall performance. Considering all the factors evaluated under conditions of this project, we believe that 'Sierra Gem' is suitable as an early cultivar. Although fruit of early-ripening cultivars are usually of a smaller size, fruit of 'Sierra Gem' were medium size (average 191.1 g) with a good flavor, and the trees were highly productive (Table 2). This cultivar can be planted on a limited scale for early market.

Based on our findings and conditions of this experiment, 'Saturn' and 'Jupiter' cultivars can be planted if "flat" peaches are in demand by the novelty market. 'Saturn' was a relatively early cultivar and was harvested between 28 July and 11 Aug. (average harvest date of 4 Aug.). This cultivar needed about 118 d to mature (between full bloom and harvest), while 'Jupiter' was harvested on 24 Aug. and needed 139 d to mature. Thus, planting both of these cultivars can provide "flat" peaches for farmers markets and local or regional consumption for several weeks. 'Saturn' and 'Jupiter' had a great appeal among consumers when fruit was harvested at ripening. However, these fruit can easily get damaged at harvest time. 
PF series cultivars had different harvest dates. While 'PF12B' and 'PFl5A' were harvested on 8 Aug. (120 and $121 \mathrm{~d}$ from full bloom), respectively, 'PF24-007' was harvested on 24 Aug. (138 d after bloom). Planting these cultivars also provides a range of harvest opportunities. PF series cultivars tested in this experiment had satisfactory overall performance. Some of these cultivars had lower SSC, but they had good flavor. We noticed that 'PF24-007' had slightly reduced bud injury under mild frost conditions.

'Sweet Dream' had good overall performance. Fruit of this cultivar have an attractive color, relatively large size (average $255.2 \mathrm{~g}$ ) with over $12 \%$ SSC, and the trees have moderately high yields. Therefore, 'Sweet Dream' can be a good choice as a lateAugust cultivar.

'August Flame' and 'O'Henry' had outstanding flavor and were two of the favorite yellow-fleshed peaches, as judged by many in the taste evaluations. 'August Flame' is a "newly released" cultivar by Burchell Nursery in California. In our evaluation, 'August Flame' seems to have a great potential for a wide-scale planting as a late-ripening cultivar due its outstanding quality and distinctively pleasant flavor. We also found 'Zee Lady' to be an excellent choice for the late-August to early-September commercial production. Fruit of this cultivar have medium size, deep dark maroon skin, and deep yellow flesh, high firmness, good storage life, and excellent flavor, while the trees had relatively high yields. 'Yukon King' and 'September Snow' had very attractive fruit with high SSC. These two cultivars, particularly 'Yukon King', were the most attractive white-fleshed peaches in our evaluation. Both of these cultivars had outstanding flavor, particularly when fruit were harvested close to the peak of ripening, as judged by the taste survey. We found through our taste survey that some people do not like white-fleshed peaches due to their low acid content. Also, many American consumers do not like white-fleshed peaches if they are firm. However, many of the same people would enjoy these peaches if they are consumed as ripe fruit.

\section{Literature cited}

Brooks, R.M. and H.P. Olmo. 1972. Register of new fruit and nut cultivars. 2nd ed. ASHS Press, Alexandria, VA.

Brooks, R.M. and H.P. Olmo. 1997. Register of new fruit and nut cultivars. 3rd ed. ASHS Press, Alexandria, VA.

Bruhn, C.M., N. Feldman, C. Garlitz, J. Hardwood, E. Ivan, M. Marshall, A. Riley, D. Thurber, and E. Williamson. 1991. Consumer perceptions of quality: Apricots, cantaloupes, peaches, pears, strawberries, and tomatoes. J. Food Qual. 14:187-195.

California Tree Fruit Agreement. 2003. California Tree Fruit Agreement 2002 annual report. California Tree Fruit Agreement, Sacramento, CA.
Crisosto, C.H., K.R. Day, G.M. Crisosto, and D. Garner. 2001. Quality attributes of white flesh peaches and nectarines grown under California conditions. J. Amer. Pomol. Soc. 55:45-51.

Frecon, J.L., R. Belding, and G. Lokaji. 2002. Evaluation of white-fleshed peach and nectarine cultivars in New Jersey. Acta Hort. 592:467-477.

Huang, H., Z. Cheng, Z. Zhang, and Y. Wang. 2008. History of cultivation and trend in China, p. 37-60. In: D.R. Layne and D. Bassi (eds.). The peach: Botany, production, and uses. CABI, Wallingford, UK.

Okie, W.R. 1998. Handbook of peach and nectarine varieties: Performance in the southeastern United States and index of names. U.S. Dept. Agr.-Agr. Res. Serv. Hdbk. No. 714.

Okie, W.R., T. Bacon, and D. Bassi. 2008. Fresh market cultivar development, p. 139-174. In: D.R. Layne and D. Bassi (eds.). The peach: Botany, production, and uses. CABI, Wallingford, UK.

Robertson, J.A., A.J. Horvat, B.G. Lyon, F.I. Meredith, S.D. Senter, and W.R. Okie. 1990. Comparison of quality characteristics of selected yellow- and whitefleshed peach cultivar. J. Food Sci. 55:1308-1311.

U.S. Department of Agriculture. 2007. Idaho tree fruit census 2006. U.S. Dept. Agr., Idaho Field Office, Boise, ID.

Whealy, K. and S. Demuth. 1993. Fruit, berry and nut inventory. 2nd ed. Seed Savers Publications, Decorah, IA.

Yost, G. and D. d'Easum. 1980. Idaho: The fruitful land. Syms-York, Boise, ID. 